Original Research Article

\title{
A study of neoplastic study of gastrointestinal tumors
}

\author{
Parmar A. ${ }^{1}$, Kokani M. J. ${ }^{2}$, Patel M. ${ }^{3}$ \\ ${ }^{1}$ Dr. Aarti Parmar, Consultant Pathologist. ${ }^{2}$ Dr. Mayur Jitubhai Kokani, Assistant Professor, Department of Pathology, \\ GMERS Medical College, Junagadh, ${ }^{3}$ Dr. Manisha Patel, Associate Professor, Department of Pathology, Government \\ Medical College, Baroda, Gujrat, India.
}

Corresponding Author: Dr. Mayur Jitubhai Kokani, Assistant Professor, Department of Pathology, GMERS Medical College, Junagadh, Gujrat, Email: mkokon11@gmail.com

\begin{abstract}
Background: Gastrointestinal tumors account for a large proportion of all neoplasms. The tumors of the Gastrointestinal tract pose a major problem in oncology and also are a major cause of apprehension in patient with the abdominal complaint in whom the fear of the cancer is the greatest. There is world wide variation in the distribution of these neoplasm, which appear largely due to exogenous factors rather than genetic. Objectives: to determine the relative frequency of various histopathologic types of tumors of eosophagus, stomach and intestines, and knowledge about their prognosis will aid the clinician in effective management of patient. Methodology: It was a prospective observational study carried after permission of the institutional ethics committee. All biopsies and resected specimens of GIT with neoplastic lesions were examined for gross lesions. All specimens studied under light microscopy and tumors were classified according to the WHO International classification of Tumors of the esophagus, stomach and intestines. Results: Gastrointestinal tumor distributed throughout all age group with maximum in $5^{\text {th }}$ and $6^{\text {th }}$ decade of life with male:female ratio was 1.67:1. Out of 18 cases of esophageal tumors, 16 were of squamous cell carcinoma, 1 case of adenosquamous carcinoma and 1 case of basaloidsquamous carcinoma. Majority of cases of gastric tumors occurred in pylorus followed closely by body of the stomach. Out of 18 cases of colorectal carcinoma, 12 cases were adenocarcinoma, 3 were mucinous adenocarcinoma, 2 cases of Signet ring cell carcinoma and 1 case of Malignant melanoma. Conclusion: Tumors of the gastrointestinal tract show a wide variation in the histological type making the histopathological examination a must in the diagnosis of these tumors. Early diagnosis and treatment is beneficial for better management and is imperative in providing better quality of life to the patient.
\end{abstract}

Keywords: Gastrointestinal track tumor, Histopathological examination, GIT neoplasm

\section{Introduction}

The neoplastic lesions of the Gastrointestinal Tract vary in different segments from oesophagus to anus. Histopathological changes in various neoplastic lesions of the gastrointestinal tract helps in proper diagnosis and deciding the mode of treatment to be offered to the patient. Gastrointestinal tumors account for a large proportion of all neoplasms [1]. Colorectal cancer ranks second and stomach cancer ranks fourth among the most common tumors of the world, according to the World Cancer Report of 2000 [2]. Curiously the small intestine is an uncommon site for tumor despite its great length and vast pool of dividing cells [1]. There is world wide variation in the distribution of these neoplasm, which appear largely due to exogenous factors rather than genetic [3].

Manuscript received: $18^{\text {th }}$ August 2017

Reviewed: $28^{\text {th }}$ August 2017

Author Corrected: $4^{\text {th }}$ September 2017

Accepted for Publication: $8^{\text {th }}$ September 2017
The tumors of the Gastrointestinal tract pose a major problem in oncology and also are a major cause of apprehension in patient with the abdominal complaint in whom the fear of the cancer is the greatest. Histopathological examination along with clinical findings and other diagnostics techniques helps to confirm the final diagnosis of various tumors of the GIT. This study is undertaken to determine the relative frequency of various histopathologic types of tumors of eosophagus, stomach and intestines, and knowledge about their prognosis will aid the clinician in effective management of patient.

\section{Materials and Methodology}

Study design and setting:It was a prospective observational study carried out over a period of 12 months by histopathology department of SSG hospital 


\section{Original Research Article}

and government medical college, Baroda in collaboration with surgery department. Human research Ethics committee permission was taken before starting the study.

Inclusion and exclusion criteria: All biopsies and resected specimens of GIT with neoplastic lesions were included in the study. While specimens of GIT without any tumor or tumor like lesions were excluded. And also endoscopic biopsy bit which is too small which may not come in block were excluded.

All surgically resected specimens of esophagus, stomach and intestines received at Department of Histopathology, Medical College and S.S.G hospital, Baroda for histopathological examination and diagnosed as neoplasm. After taking informed written consent of the patient detailed clinical history along with clinical findings were elaborated and noted. Evidence of metastasis was checked. Grading and staging was done in each patient. The specimen was then dissected, gross features of the tumor was described and kept for fixation in $10 \%$ formalin for 12 36 hours. Standardized tissue bits were sampled from the tumor, surgical margins and lymphnodes, if identified and processed in automated histokinette and embedded in paraffin wax. Sections of 4-6 $\mu$ thickness were cut using semi-automated microtome and stained with Haematoxylin and Eosin stain. Special stains and IHC were used, wherever necessary.

The histological features were studied under light microscopy and tumors were classified according to the WHO International classification of Tumors of the esophagus, stomach and intestines. Statistical analysis was done using Microsoft excel.

\section{Results}

According to inclusion and exclusion criteria total 48 cases could be enrolled in the study during one year. Age wise distribution shows Tumors of esophagus, stomach and large intestines had wide variation in age distribution. And among them 5 th and 6 th decade of life had the highest occurrence of gastrointestinal carcinoma with total 27 [56\%] cases. [Table 1] The study showed there was a male predominance with the male to female ratio of 1.67:1 [Table 2].

Majority $(93.75 \%)$ of the cases were of epithelial origin while the mesenchymal tumors and lymphomas constituted $6.25 \%$. [Table 3]. On clinical examination lymph nodes were identified in 16 cases out of which metastatic deposits were seen only in 10 cases on histological examination, which constitutes $20.84 \%$ of all cases. Colon and rectal tumor had highest numbers of lymphnode enlargement [Table 4].

Table-1: Age wise distribution of all cases.

\begin{tabular}{|c|c|c|c|c|c|c|}
\hline $\begin{array}{c}\text { Age } \\
\text { (years })\end{array}$ & Esophagus & Stomach & $\begin{array}{c}\text { Small } \\
\text { intestine }\end{array}$ & $\begin{array}{c}\text { Colon and } \\
\text { rectum }\end{array}$ & Anal canal & Total (\%) \\
\hline $11-20$ & - & - & - & 1 & - & $1(2.08)$ \\
\hline $21-30$ & 1 & - & - & 3 & - & $4(8.33)$ \\
\hline $31-40$ & 1 & 1 & - & 2 & 2 & $6(12.5)$ \\
\hline $41-50$ & 7 & 3 & 1 & 3 & - & $14(29.17)$ \\
\hline $51-60$ & 7 & 2 & - & 4 & - & $13(27.08)$ \\
\hline $61-70$ & 2 & - & - & 4 & 1 & $7(14.59)$ \\
\hline $71-80$ & - & - & 1 & 1 & 1 & $3(6.25)$ \\
\hline Total & $\mathbf{1 8}$ & $\mathbf{6}$ & $\mathbf{2}$ & $\mathbf{1 8}$ & $\mathbf{4}$ & $\mathbf{4 8}(\mathbf{1 0 0})$ \\
\hline
\end{tabular}

Table-2: Gender wise and anatomical distribution of all gastrointestinal tumors.

\begin{tabular}{|c|c|c|c|}
\hline Site & Male & Fe male & Total \\
\hline Esophagus & 13 & 5 & $18(37.5)$ \\
\hline Stomach & 4 & 2 & $6(12.5)$ \\
\hline Small Intestine & 1 & 1 & $2(4.16)$ \\
\hline Appendix & - & - & - \\
\hline Colon and Rectum & 10 & 8 & $\mathbf{1 8}(\mathbf{3 7 . 5})$ \\
\hline Anal Canal & 2 & 2 & $4(8.34)$ \\
\hline Total & $\mathbf{3 0}$ & $\mathbf{1 8}$ & $\mathbf{4 8}(\mathbf{1 0 0})$ \\
\hline
\end{tabular}




\section{Original Research Article}

Table-3: Histological types of tumors of GIT.

\begin{tabular}{|c|c|c|c|c|c|c|c|}
\hline Site & Esophagus & Stomach & Smallintestine & $\begin{array}{c}\text { Colonand } \\
\text { Rectum }\end{array}$ & $\begin{array}{c}\text { Anal } \\
\text { Canal }\end{array}$ & Total & Percentage \\
\hline Epithelial & 18 & 4 & 2 & 17 & 4 & 45 & 93.75 \\
\hline Mesenchymal & - & 1 & - & 1 & - & 2 & 4.17 \\
\hline Lymphoma & - & 1 & - & - & - & 1 & 2.08 \\
\hline Total & $\mathbf{1 8}$ & $\mathbf{6}$ & $\mathbf{2}$ & $\mathbf{1 8}$ & $\mathbf{4}$ & $\mathbf{4 8}$ & $\mathbf{1 0 0}$ \\
\hline
\end{tabular}

Table-4 : Metastatic lymph nodes in tumors of GIT.

\begin{tabular}{|c|c|c|}
\hline Site & Gross & Metastasis \\
\hline Esophagus & 1 & 3 \\
\hline Stomach & 3 & 1 \\
\hline Small Intestine & 2 & - \\
\hline Appendix & - & - \\
\hline Colon and Rectum & 9 & $\mathbf{1 0}$ \\
\hline Anal Canal & $\mathbf{1 6}$ & 4 \\
\hline Total & & \\
\hline
\end{tabular}

Table-5: histological variant tumors of various sites.

\begin{tabular}{|c|c|}
\hline Tumor Variant & Number \\
\hline \multicolumn{2}{|c|}{ Esophageal tumors } \\
\hline Adenocarcinoma & - \\
\hline Adenosquamous & 1 \\
\hline Squamous cell carcinoma & 16 \\
\hline Basaloidsquamous & 1 \\
\hline \multicolumn{2}{|c|}{ Gastric tumors } \\
\hline Adenocarcinoma & 3 \\
\hline Signetring adenocarcinoma & 1 \\
\hline Diffuse large Bcell lymphoma & 1 \\
\hline GIST & 1 \\
\hline \multicolumn{2}{|c|}{ Small Intestinal tumor } \\
\hline Adenocarcinoma & 2 \\
\hline \multicolumn{2}{|c|}{ Colon and Rectal tumor } \\
\hline Adenocarcinoma & 12 \\
\hline Mucinous Adeno Ca & 3 \\
\hline Signet ring cell $\mathrm{Ca}$ & 2 \\
\hline Squamous cell $\mathrm{Ca}$ & - \\
\hline Melignant melanoma & 1 \\
\hline Undifferentiated $\mathrm{Ca}$ & - \\
\hline \multicolumn{2}{|c|}{ Anal canal tumor } \\
\hline Mucinous adenocarcinoma & 1 \\
\hline Adenocarcinoma & 3 \\
\hline Total & 48 \\
\hline
\end{tabular}




\section{Original Research Article}

Out of 18 cases of esophageal tumors, 16 were of squamous cell carcinoma, 1 case of adenosquamous carcinoma and 1 case of basaloidsquamous carcinoma [Table 5]. The esophageal squamous cell Carcinoma were graded according to their histological differentiation and most of them (8) were seen to be well differentiated.

Majority of cases of gastric tumors occurred in pylorus (3) followed closely by body of the stomach (2) [Table 6]. Most of the tumors were seen on the luminal aspect as a firm and necrotic lesion. Also one lesion was ulceroinfiltrative and one lesion was nodular. Out of 6 cases of gastric tumors, 4 were of adenocarcinoma constituting $66.6 \%$. The other 1 case of diffuse large B cell lymphoma and 1 case of Gastrointestinal stromal tumor (GIST) constituting 33.3\% [Table 5]. Figure 1 is the GIST of stomach showing immunoreactivity for CD117. The mesenchymal tumor which occurred in the stomach was gastrointestinal stromal tumor. Grossly it appeared as a two nodule measuring $3.5 \times 2 \times 1 \mathrm{~cm}$. Histologically, the tumor was composed of spindle cells signet ring like cells and epithelioid cells. It was confirmed the same on IHC.

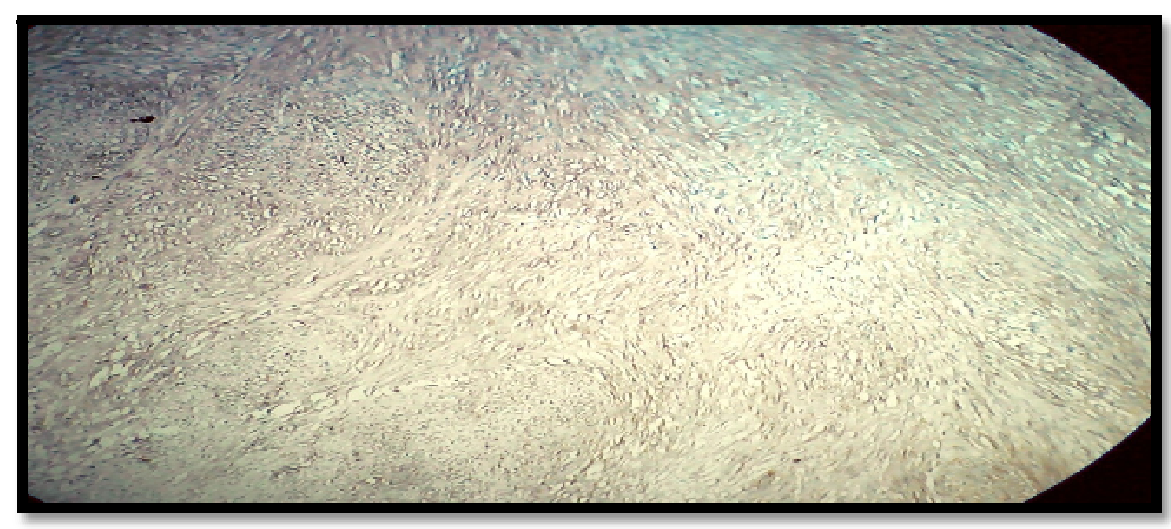

Figure-1: GIST of stomach showing immunoreactivity for CD117

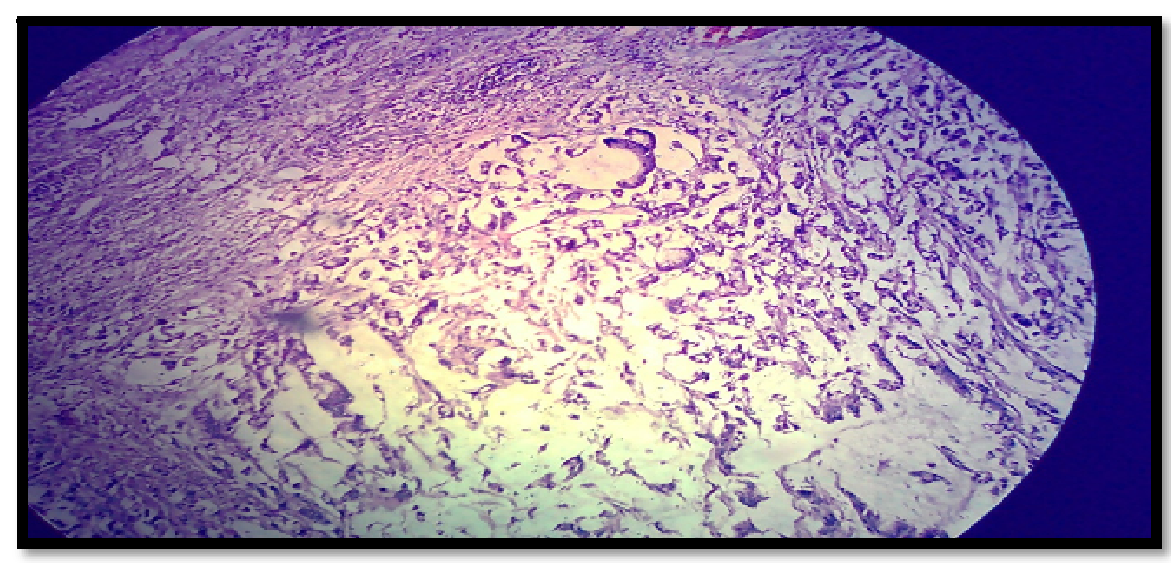

Figure -2: Signet Ring Carcinoma Rectum

Only two cases of small intestinal tumors were seen. One was located in the ileocaecal segment and other was located in the duodenum. Male to Female ratio is 1:1 with their age being 50 and 75 years. Both the cases were of Adenocarcinoma, moderately differentiated type.

Table 6: Anatomical distribution of gastric tumors.

\begin{tabular}{|c|c|c|}
\hline Site & Number & Percentage \\
\hline Cardia & $\mathbf{1}$ & $\mathbf{1 6 . 6 6}$ \\
\hline Fundus & - & - \\
\hline Body & 2 & 33.34 \\
\hline Antrum & - & - \\
\hline Pyloric Canal & 3 & 50.00 \\
\hline Total & $\mathbf{6}$ & $\mathbf{1 0 0}$ \\
\hline
\end{tabular}


Original Research Article

Table-7: Anatomical distribution of colorectal carcinoma.

\begin{tabular}{|c|c|c|}
\hline Site & Number & Percentage \\
\hline Caecum & 0 & 0 \\
\hline Ascending Colon & 1 & 5.55 \\
\hline Transverse Colon & 2 & 11.12 \\
\hline Descending Colon & 1 & 5.55 \\
\hline Sigmoid Colon & 2 & 11.12 \\
\hline Rectum & 8 & 44.44 \\
\hline Rectosigmoid & 4 & 22.22 \\
\hline Total & $\mathbf{1 8}$ & $\mathbf{1 0 0}$ \\
\hline
\end{tabular}

Rectum was the commonest site constituting $44.44 \%$ of colorectal malignancies colorectal tumors. [Table 7] Grossly most of the cases (5) presented as an ulcero infiltrative lesion, while 2 cases were exophytic and one case was fungating. Out of 18 cases, 12 cases were adenocarcinoma. The others were 3 cases of mucinous adenocarcinoma, 2 cases of Signet ring cell carcinoma [figure 2] and 1 case of Malignant melanoma [Table 5]. Grossly lymphnodes were identified in 9 cases while metastasis was seen only in 4 cases on microscopic examination.

Of the 4 cases of anal canal 1(25\%) case was mucinous adenocarcinoma and 3 cases(75\%) were Adenocarcinoma, moderately differentiated type.

\section{Discussion}

Gasrointestinal tract are some of the common neoplasms encountered in India. They demonstrate an array of histological patterns, varied clinical presentations, an assortment of gross patterns and an immense variability in their prognosis. They also show marked geographic variation in the anatomical sites involved. As in western countries frequencies are decreasing. Considering the numerous variables involved, it would be justified in undertaking an in-depth study into tumors of Gasrointestinal tract. A total of 48 cases were studied from October 2013 to October 2014.

Tumors of GIT were seen over a wide range of age (12 years to 80 years). The highest distribution was found in the 5th decade, which was consistent with the study by Prabhakar et al [4]. However the peak distribution was 6th and 7th decade in study done by SfoortiGoswami et al [1] and Mohammad et al [5] respectively. A male predominance was observed in this study with a male to female ratio of 1.67:1. This ratio is less when compared with studies of SfoortiGoswami et al [1] and Prabhakar et al [4] while the ratio is more when compared with study of Mohammad et al46 where the ratio is $1.25: 1$ The site distribution of various tumors varies with the geographic location. Stomach carcinoma is the fourth most common cancer and colorectal is the second commonest cancer worldwide. There has been a dramatic decline in the incidence of stomach cancer, which can be due to early diagnosis and treatment of H.pylori infections. In the present study, the commonest site for malignant tumor was the Large intestine constituting $45.84 \%$, followed by tumors of Esophagus which constitutes $37.5 \%$ of the cases.

In present study, $77.78 \%$ of esophageal tumors were in the age group of 40-60 years. Leena Devi et al [6] in 1980 reported a maximum number of cases i.e. $33.8 \%$ were in the age group of 51-60 yrs. Mohammed et al [5] in 2006 reported a maximum number of cases were in the age group of 21-30 yrs. Ahmed Mohammed Afroz et al [7] in 2012 reported a maximum number of cases i.e. $44.11 \%$ were in the age group of $61-70 \mathrm{yrs}$. According to the histology in the present study, 88.88\% cases were squamous cell carcinoma, 1 case $(5.56 \%)$ cases was adenosquamous carcinoma and 1 case $(5.56 \%)$ cases was basaloidsquamous carcinoma. Ahmed Mohammed Afroz et al [7] reported 96\% cases to be of squamous cell carcinoma and $4 \%$ cases to be of adenocarcinoma. In the present study $5.56 \%$ cases of adenosquamous carcinoma were reported in the esophagus. Gal et al [8] reported $3.48 \%$ cases of adenosquamous carcinoma in the esophagus.

Age distribution shows that $50 \%$ cases of gastric tumor were present in age range of $41-50$ years. In the study M.Lavanya et al [9], 2012, 37.57\% cases being reported in the age range of 41-50 years. In the study Ahmed MohammedAfroz et al [7], 46.67\%\% cases being reported in the age range of 41-50 years. Thus the tumors of the stomach are commoner in 41-50 years of 


\section{Original Research Article}

age group and the result of the present study are similar with studies of M. Lavanya et al [9], 2012 and Ahmed Mohammed Afroz et al [7]. In the present study, $66.67 \%$ cases were adenocarcinoma, $16.67 \%$ cases were diffuse large B cell lymphoma, and $16.67 \%$ cases were GIST.Out of 4 cases of adenocarcinoma, 1 case $16.67 \%$ was belonged to the signet ring variety. Mohammed et al [5], 2006 reported adenocarcinoma to be commonest tumor of the stomach. Ahmed Mohammed Afroz et al [7], also reported adenocarcinoma to be commonest tumor of the stomach. Lewin et al [10] in 1978 reported $48 \%$ cases of lymphoma, and M. Lavanya et al [9] reported $12.5 \%$ cases of lymphoma. Stomach is the commenest site for GIST.

Small intestinal tumors are relatively rare and constitute only $3-6 \%$ of all gastrointestinal tumors in spite of constituting $75 \%$ of the length and $90 \%$ of the mucosal surface of the alimentary tract. Only 2 cases were reported in the present study (4.16\% of all cases), first was in the ileum and the age was 50 year. Second was in the duodenum and the age was 75 year. In the study by Mohammad et al [5], by only 2 cases being reported in small intestine. In conformity with study by Shahid Jamal et al, [11] there was a male predominance (M:F2.6:1) and the common site of occurrence of lymphoma was ileum. The study done in China by Zhi-Wei et al [12] showed a male predominance with average age of occurrence being 47 years. Leiomyosarcoma has the highest occurrence followed closely by adenocarcinomas, and the commonest site of occurrence being the ileum.

Tumors of the colon and rectum are the commonest tumors in the gastrointestinal tract in the Western World. However, in India these tumors are relatively rare, but its incidence is increasing and varies from place to place. In the present study, 18 cases were from the colorectal region constituting the $37.5 \%$ of all cases. Thus the maximum number of cases in the present study were in the age range of 51-70 years. M.Lavanya et al [9] in 2012 reported maximum cases in 51-60 years age range.

According to the histology in the present study, adenocarcinoma accounted for $94.44 \%$ of 18 cases studied in the large intestine. Only one case $(5.56 \%)$ was Malignant melanoma. Leena Devi et al [6] in her study of 260 cases of malignancies reported $86.15 \%$ cases of adenocarcinoma, $5.38 \%$ of squamous cell carcinomas and $4.23 \%$ of undifferentiated carcinomas. Leiomyosarcomas accounted for $0.77 \%$ while lymphomas accounted for $2.31 \%$.
Only 4 cases of tumor of anal canal region was reported $8.34 \%$ of all cases. Out of them $3(75 \%)$ cases were adenocarcinoma and $1(25 \%)$ case was mucinous adenocarcinoma. They were reported in the age range of 31-75 years. Since only 4 cases were reported in the present study, comparisons with other studies were insignificant.

\section{Conclusion}

Tumors of the gastrointestinal tract show a wide variation in the histological type making the histopathological examination a must in the diagnosis of these tumors. Early diagnosis and treatment is beneficial for better management and is imperative in providing better quality of life to the patient.

Funding: Nil, Conflict of interest: None initiated, Permission from IRB: Yes

\section{References}

1. Goswami S, Bhalara R, Talweklar S, Dalsania J, Agravat A, Dhruva G. Histopathological study of Gastrointestinal Tumors, A three year study at PDU Medical College.Rajkot.Int J Res Med 2013;2(3);78-81.

2. Colin Mathers, Cynthia Boschi-Pinto. Global burden of cancer in the year 2000: Version 1 estimates. World Health Organization, Global Program on Evidence for Health Policy (GPE).Available from: http:// www. who. int/healthinfo/statistics/bod_malignantneoplasmscancer s.pdf

3. National Research Council (US) Committee on Diet, Nutrition, and Cancer. Diet, Nutrition, and Cancer. Washington (DC): National Academies Press (US); 1982. 16 Cancer Incidence and Mortality. Available from: https: //www. ncbi. nlm. nih. gov/books /NBK 216650 .

4. Prabhakar BR, Prabhakar H, Tung BS. Gastrointestinal Malignant tumors in Amristsar (Punjab). Indian Journal of Surgery 1981; 343-5.

5. Mohammad A, Makaju R. Retrospective histopathological analysis of various neoplasms of different parts of the gastrointestinal tract seen at the Kathmandu University Teaching Hospital, Dhulikhel, Nepal. Kathmandu University Medical Journal 2006;4: 474-8.

6. Devi Leena KR, Suvarna N. Pattern of gastrointestinal tumours in North Kerala. 1980 Sep;17 (3): 159-63. 


\section{Original Research Article}

7. Dissertation by Dr. Mohammad Afroz Ahmed. "Histopathological study of neoplastic lesion of upper Gastrointestinal tract by endoscopic biopsy" Mysore Medical college and Research Institute, Rajiv Gandhi University of Health \& sciencies, Karnataka, Bangalore, April - 2012.

8. Cerar A, Jutersek A, Vidmar S. Adenoid cystic carcinoma of the esophagus. A clinicopathologic study of three cases. Cancer 1991;67:2159-2164.

9. Dissertation by Dr. M. Lavanya, Dr. R. Sreelatha, "histopathological study of tumours of stomach and intestines" Rajiv Gandhi university of health sciences, Karnataka, Bangalore. April - 2010.
10. Lewin KJ, Ranchod M, Dorfman RF. Lymphomas of the gastrointestinal tract: a study of 117 cases presenting with gastrointestinal disease. Cancer. 1978 Aug; 42 (2):693-707.

11. Jamal S, Mamoon N, Mushtaq S, Luqman M. Analysis of gastrointestinal malignancies at the Armed Forces Institute of Pathology (AFIP), Rawalpindi, Pakistan. Asian Pac J Cancer Prev. 2005 Oct-Dec;6(4): 497-500.

12. Zhou Z-W, Wan D-S, Chen G, Chen Y-B, Pan Z-Z. Primary malignant tumor of the small intestine. World Journal of Gastroenterology. 1999;5(3):273-276. doi:10. 3748/wjg.v5.i3.273.

\section{How to cite this article?}

Parmar A, Kokani M. J, Patel M. A study of neoplastic study of gastrointestinal tumors. Trop J Path Micro 2018;4(1):2733.doi: 10.17511/jopm.2018.i1.05. 